\title{
A novel bacterial thiosulfate oxidation pathway provides a new clue about the formation of zero-valent sulfur in deep sea
}

\author{
Jing Zhang ${ }^{1,2,3,4} \cdot$ Rui Liu ${ }^{1,2,4} \cdot$ Shichuan $\mathrm{Xi}^{3,4,5} \cdot$ Ruining Cai ${ }^{1,2,3,4} \cdot$ Xin Zhang ${ }^{4,5} \cdot$ Chaomin Sun ${ }^{1,2,4}$
}

Received: 18 December 2019 / Revised: 6 May 2020 / Accepted: 12 May 2020 / Published online: 26 May 2020

(c) The Author(s) 2020. This article is published with open access

\begin{abstract}
Zero-valent sulfur (ZVS) has been shown to be a major sulfur intermediate in the deep-sea cold seep of the South China Sea based on our previous work, however, the microbial contribution to the formation of ZVS in cold seep has remained unclear. Here, we describe a novel thiosulfate oxidation pathway discovered in the deep-sea cold seep bacterium Erythrobacter flavus 21-3, which provides a new clue about the formation of ZVS. Electronic microscopy, energy-dispersive, and Raman spectra were used to confirm that E. flavus 21-3 effectively converts thiosulfate to ZVS. We next used a combined proteomic and genetic method to identify thiosulfate dehydrogenase (TsdA) and thiosulfohydrolase (SoxB) playing key roles in the conversion of thiosulfate to ZVS. Stoichiometric results of different sulfur intermediates further clarify the function of TsdA in converting thiosulfate to tetrathionate $\left({ }^{-} \mathrm{O}_{3} \mathrm{~S}-\mathrm{S}-\mathrm{S}-\mathrm{SO}_{3}{ }^{-}\right)$, SoxB in liberating sulfone from tetrathionate to form $\mathrm{ZVS}$ and sulfur dioxygenases (SdoA/SdoB) in oxidizing ZVS to sulfite under some conditions. Notably, homologs of TsdA, SoxB, and $\mathrm{SdoA} / \mathrm{SdoB}$ widely exist across the bacteria including in Erythrobacter species derived from different environments. This strongly indicates that this novel thiosulfate oxidation pathway might be frequently used by microbes and plays an important role in the biogeochemical sulfur cycle in nature.
\end{abstract}

\section{Introduction}

Zero-valent sulfur (ZVS) is widespread under the sea floor [1], particularly in the cold seep and the hydrothermal

Supplementary information The online version of this article (https:// doi.org/10.1038/s41396-020-0684-5) contains supplementary material, which is available to authorized users.

Chaomin Sun

sunchaomin@qdio.ac.cn

1 CAS Key Laboratory of Experimental Marine Biology \& Center of Deep Sea Research, Institute of Oceanology, Chinese Academy of Sciences, Qingdao, China

2 Laboratory for Marine Biology and Biotechnology, Qingdao National Laboratory for Marine Science and Technology, Qingdao, China

3 College of Earth Science, University of Chinese Academy of Sciences, Beijing, China

4 Center of Ocean Mega-Science, Chinese Academy of Sciences, Qingdao, China

5 CAS Key Laboratory of Marine Geology and Environment \& Center of Deep Sea Research, Institute of Oceanology, Chinese Academy of Sciences, Qingdao, China system [2-4]. The production of ZVS is an important energy-conserving strategy for prokaryotes inhabiting these areas. Intimately associated with microbial cells, ZVS is regarded as a bio-signature of the activity of sulfuroxidizing microorganisms [5-7]. The process of ZVS production begins with the formation of polysulfide, which has been implicated in a number of important geochemical reactions, such as pyritization [8]. Cyclooctasulfur $S_{8}$ and inorganic polysulfide $\left(\mathrm{S}_{\mathrm{n}}{ }^{2-}\right)$ are important forms of ZVS, which is a critical intermediate in the biogeochemical sulfur cycle $[9,10]$.

As a common substrate oxidized by almost all sulfur lithotrophs, thiosulfate has been suggested to fulfill a key role in the sulfur cycle [11]. At least three thiosulfate oxidation pathways are postulated to exist in sulfur oxidizing bacteria $[12,13]$, and each has the possibility to form ZVS either extra- or intracellularly. The first is the Sox pathway, which is governed by the conserved operon SoxXYZABCD and operates in photo- and chemo-lithotrophic alphaproteobacteria $[14,15]$. The oxidation of thiosulfate is performed via a multienzyme complex consisting of the thiosulfate-induced periplasmic proteins SoxAX, SoxYZ, SoxB, and SoxCD. The complete Sox pathway results in sulfate as the sole product, whereas the incomplete pathway 
(with SoxCD absent) results in either intra- [16-19] or extracellular [20] accumulation of ZVS. However, the colorless sulfur bacteria Thiomicrospira thermophile, which contains a complete Sox pathway, exhibits $\mathrm{pH}$-dependent thiosulfate oxidation to either extracellular ZVS and sulfate at low $\mathrm{pH}$ (incomplete) or sulfate only at alkaline $\mathrm{pH}$ (complete) [21].

The second thiosulfate oxidation pathway is the tetrathionate intermediate $\left(\mathrm{S}_{4} \mathrm{I}\right)$ pathway, which involves production and consumption of polythionate [22]. $\mathrm{S}_{4} \mathrm{I}$ is widely found in Beta- and Gammaproteobacteria, particularly the obligate chemolithotrophic genera including Acidithiobacillus, Thiobacillus, Halothiobacillus, Thermithiobacillus, and Advenella [23, 24]. The production of tetrathionate is likely coupled with enzymes that subsequently split tetrathionate to thiosulfate, sulfate, or elemental sulfur [25, 26]. In addition, the Betaproteobacteria Advenella kashmirensis either oxidizes tetrathionate to sulfate or uses it as an intermediate during thiosulfate oxidation [27].

The third thiosulfate oxidation pathway is branched thiosulfate oxidation, comprehensively characterized in the purple sulfur bacterium Allochromatium vinosum, and this pathway involves the interaction of Sox- and $\mathrm{S}_{4}$ I-related enzyme systems $[16,28]$. Under neutral or slightly acidic growth conditions thiosulfate dehydrogenase (TsdA) catalyzes some of the thiosulfate to tetrathionate, while thiosulfate oxidizes to sulfate with the formation of sulfur globules through the Sox system. In conjunction with the dissimilatory sulfite reductase system, sulfur globules are further oxidized to sulfate [29].

Sulfur oxidizing bacteria are defined as microbes that use reductive sulfur compounds as an energy source for growth. They are highly diverse, and include the green and purple sulfur bacteria, purple non-sulfur bacteria and colorless sulfur bacteria. All green sulfur bacteria belong to the phylum Chlorobi and most oxidize sulfide and ZVS to sulfate [20]. Purple sulfur bacteria include the families Chromatiaceae and Ectothiorhodospiraceae and produce intra- and extracellular sulfur when grown in the presence of sulfide and thiosulfate [29]. Purple non-sulfur bacteria are a highly diverse and heterogeneous group of bacteria [30] that prefer photoheterotrophic growth under anaerobic conditions, and include many species that can grow photoautotrophically with hydrogen or sulfide as the electron donor. The colorless sulfur bacteria are often identified as chemolithoautotrophic, chemolihoheterotrophic, or chemoorganoheterotrophic [31]. The famous genera in this group include Thiobacillus, Acidithiobacillus, Halothiobacillus, and Beggiatoa [10, 32].

The genus Erythrobacter belongs to the family Erythrobacteraceae, members of which have been isolated from seawater, tidal flats, marine sediment, marine invertebrates, and other ecosystems [33]. Family members of
Erythrobacteraceae offer a valuable source for further studies focused on aerobic anoxygenic phototrophic metabolism [34, 35], carbon cycling in the ocean [36], and have high potential for applications in biotechnology because they contain important enzymes, such as epoxide hydrolase [37, 38] and manganese oxydase [39]. The genus Erythrobacter is abundant in different marine environments [40-42] including the deep-sea cold seep where the relative abundance of Erythrobacter could reach $4 \%$ of the total bacterial community [43], which strongly suggests that Erythrobacter plays an important ecological role in the deep-sea cold seep. However, to the best of our knowledge, the involvement of Erythrobacter in the oxidation of thiosulfate and other reductive sulfur compounds has not been elucidated.

In our previous study, a large amount of ZVS was found in the chemosynthetic communities of the Formosa Ridge cold seep in the South China Sea, suggesting that ZVS may be a key intermediate in the sulfur cycle in the deep-sea cold seep [4]. However, the microbial contribution to the formation of ZVS was unknown. Here, we report a novel thiosulfate oxidation pathway in Erythrobacter (and other bacteria), that provides a new clue about the formation of ZVS in the deep-sea cold seep. The key genes responsible for thiosulfate oxidation and ZVS production in E. flavus 21-3 were determined by a combination of proteomic, genetic, and stoichiometric methods. The broad distribution of these genes was investigated and discussed.

\section{Materials and methods}

\section{Bacterial strains, plasmids, primers, and growth conditions}

E. flavus 21-3 was isolated from sediment samples collected by RV KEXUE from the cold seep in the South China Sea $\left(119^{\circ} 17^{\prime} 04.956^{\prime \prime} \mathrm{E}, 22^{\circ} 06^{\prime} 58.384^{\prime \prime} \mathrm{N}\right)$ at a depth of $\sim 1143 \mathrm{~m}$ in September 2017 (Supplementary Table S1). The $\sim 0.5 \mathrm{~g}$ sediment sample was added to $100 \mathrm{~mL}$ of sulfur producing medium (SPM). The SPM contained: $10 \mathrm{~g}$ $\mathrm{Na}_{2} \mathrm{~S}_{2} \mathrm{O} \cdot 5 \mathrm{H}_{2} \mathrm{O}, 0.2 \mathrm{~g} \mathrm{~K}_{2} \mathrm{HPO}_{4}, 1 \mathrm{~g} \mathrm{NaHCO}_{3}, 0.4 \mathrm{~g} \mathrm{NH}_{4} \mathrm{Cl}$, $0.6 \mathrm{~g} \mathrm{MgSO}_{4}, 0.001 \mathrm{~g} \mathrm{FeCl}_{3}$, and $0.001 \mathrm{~g} \mathrm{MnCl}_{2}$ in $1 \mathrm{~L}$ of sea water, and $15 \mathrm{~g} / \mathrm{L}$ agar was added to make the corresponding solid medium. Samples were incubated at $28^{\circ} \mathrm{C}$ with shaking at a speed of $150 \mathrm{rpm}$ for 2 days. For isolation of single colony, gradient dilutions were made before spread plating. Genomic DNA was extracted (water-boiling) from the isolates, and PCR was performed to amplify the 16S rRNA gene sequence as described previously [44]. To determine the phylogenetic position of E. flavus 21-3, the 16S rRNA gene sequence was analyzed by the BLAST programs (https://blast.ncbi.nlm.nih.gov/Blast.cgi), and the 
phylogenetic tree was reconstructed with MEGA X [45]. Pairwise genome comparison using Average Nucleotide Identity (ANI) based on ANIb was performed with PYANI [46].

E. flavus 21-3 wild type and the corresponding mutants were cultured at $28{ }^{\circ} \mathrm{C}$ in artificial seawater (ASW) marine broth $2216 \mathrm{E}(5 \mathrm{~g}$ tryptone and $1 \mathrm{~g}$ yeast extract in $1 \mathrm{~L}$ ASW). $1 \mathrm{M}$ thiosulfate stock was added to the autoclaved medium after filtration through $0.22-\mu \mathrm{m}$ nuclepore tracketched membranes (Whatman, England). The ASW contained: $24.47 \mathrm{~g} \mathrm{NaCl}, 3.917 \mathrm{~g} \mathrm{Na}_{2} \mathrm{SO}_{4}, 0.664 \mathrm{~g} \mathrm{KCl}$, $0.024 \mathrm{~g} \mathrm{SrCl}, 4.981 \mathrm{~g} \mathrm{MgCl} \cdot 6 \mathrm{H}_{2} \mathrm{O}, 1.102 \mathrm{~g} \mathrm{CaCl}_{2}, 0.192 \mathrm{~g}$ $\mathrm{NaHCO}_{3}, 0.026 \mathrm{~g} \mathrm{H}_{3} \mathrm{BO}_{4}$, and $0.0039 \mathrm{~g} \mathrm{NaF}$ per $1 \mathrm{~L}$ of Milli-Q water. The $\mathrm{pH}$ was adjusted to between 7.2 and 7.5 using $1 \mathrm{M} \mathrm{NaOH}$. Diluted (tenfold) 2216E medium with or without $40 \mathrm{mM}$ thiosulfate was used to observe the production of extracellular sulfur globules. Escherichia coli was grown and maintained at $37^{\circ} \mathrm{C}$ in Luria-Bertani (LB) broth or on agar-plates (supplemented with appropriate antibiotic (s) as required). The bacterial strains, plasmids, and primers used in this study are listed in Supplementary Table S2. Antibiotics were added at the following concentrations when necessary: ampicillin, $100 \mu \mathrm{g} / \mathrm{mL}$; chloramphenicol, $25 \mu \mathrm{g} / \mathrm{mL}$, and gentamicin, $25 \mu \mathrm{g} / \mathrm{mL}$.

\section{Electron microscopic analysis of sulfur globules}

Scanning electron microscope (SEM) (S-3400N; Hitachi, Japan), transmission electron microscope (TEM) (HT7700; Hitachi, Japan) and Raman spectra (WITec alpha300 R system; WITec Company, Germany) were used to identify the components and structure of sulfur globules produced by E. flavus 21-3. For SEM analysis, a milky white suspension was collected by centrifugation (5000 rpm, $10 \mathrm{~min}$ ), lyophilized and observed at $5 \mathrm{kV}$. Energy-Dispersive Spectrum (EDS) (model 550i, IXRF systems, USA) equipment with SEM and TEM was employed at an accelerating voltage of $5 \mathrm{keV}$ for $30 \mathrm{~s}$. The sulfur globules were observed at $80 \mathrm{kV}$ with TEM after being separated by ultracentrifugation according to the method described in Müller et al. [47] with some modifications. Briefly, $10 \mathrm{~mL}$ culture of E. flavus 21-3 (cultured with $40 \mathrm{mM}$ thiosulfate) was centrifuged twice at $8000 \mathrm{rpm}$ for $20 \mathrm{~min}$, after which the supernatant was centrifuged at $12,000 \mathrm{rpm}$ for $20 \mathrm{~min}$, to remove debris and cells. The supernatant was collected and centrifuged at $31,000 \mathrm{rpm}$ for $2 \mathrm{~h}$ at $8^{\circ} \mathrm{C}$ in a Beckman SW $40 \mathrm{Ti}$ rotor (California, USA). The pellets were resuspended in $2 \mathrm{~mL}$ buffer $(10 \mathrm{mM}$ Tris- $\mathrm{HCl}, 100 \mathrm{mM}$ $\mathrm{NaCl}, 5 \mathrm{mM} \mathrm{CaCl}_{2}$ ). TEM for the observation of E. flavus 21-3 cultured with $40 \mathrm{mM}$ thiosulfate was conducted at $120 \mathrm{kV}$.

\section{Proteome analysis}

For proteomic profiling, E. flavus 21-3 was grown in $100 \mathrm{~mL}$ of $2216 \mathrm{E}$ medium with or without $40 \mathrm{mM}$ thiosulfate. Cells were harvested after $18 \mathrm{~h}$ or $36 \mathrm{~h}$ of incubation, and three biological replicates were completed. Cells were harvested by centrifugation at $12,000 \mathrm{rpm}$ for $10 \mathrm{~min}$ at $4{ }^{\circ} \mathrm{C}$, and the pellets were washed with $10 \mathrm{mM}$ phosphate buffer solution (PBS pH 7.4), resuspended in lysis buffer (8 M urea, $1 \%$ Protease Inhibitor Cocktail) and disrupted by sonication. The remaining debris was removed by centrifugation at 12,000 rpm at $4{ }^{\circ} \mathrm{C}$ for $10 \mathrm{~min}$. Finally, the supernatant was collected and the protein concentration was determined with a BCA kit according to the manufacturer's instructions. Trypsin digestion, TMT labeling, HPLC fractionation, LC-MS/MS analysis, database search and bioinformatics analysis are described in detail in the supplementary information. Analysis of the differentially expressed proteins was performed using HemI software [48].

\section{Recombinant DNA techniques}

Standard methods for DNA manipulation and cloning were used unless otherwise indicated [49]. KOD One ${ }^{\mathrm{TM}}$ PCR Master Mix, Ligation high, ReverTra Ace qPCR RT Master Mix and Realtime PCR Master Mix were obtained from TOYOBO (Osaka, Japan) and used according to the manufacturer's instructions. Restriction enzymes (FastDigest) were obtained from Thermo Scientific (Waltham, USA). The genotype of the E. flavus 21-3 mutant strains generated in this study was confirmed by PCR using the $2 x$ Rapid Taq Master Mix (Vazyme Biotech Co., Ltd, Nanjing, China). Plasmid DNA from E. coli was purified using the Insight-ExBio Plasmid Miniprep kit (Qingdao, China). Purification of PCR product was using TIANgel Purification Kit (Beijing, China).

\section{Construction of $E$. flavus 21-3 mutant strains}

Homologous recombination techniques were used to generate knockout mutations in E. flavus 21-3 according to the method described previously [50] with some modifications. To mutate $t s d A$ (locus tag D0Y83_01395), the upstream and downstream flanking regions of the ORF were amplified from the wild type E. flavus 21-3 genome using primers tsdA-up_F/tsdA-up_R and tsdA-down_F/tsdA-down_R (Supplementary Table S2), respectively. The upstream and downstream PCR products were purified, combined, and used as templates for an overlap extension PCR of KO-tsdA using primers tsdA-up_F/tsdA-down_R. The KO-tsdA fragment was purified, digested and inserted into the suicide vector pEX-18Gm via EcoRI and BamHI restriction sites. The resulting plasmid (pEX-18Gm-KO-tsdA) was 
transformed sequentially into E. coli $\mathrm{SY} 327$ and $E$. coli S17-1 using the $\mathrm{CaCl}_{2}$ method. Mating between E. flavus 21-3 and E. coli S17-1 containing pEX-18Gm-KO-tsdA was cultured at $28^{\circ} \mathrm{C}$ for at least $72 \mathrm{~h}$. Single-event recombinant strains were selected on $2216 \mathrm{E}$ agar plate supplemented with ampicillin and gentamicin. Colonies containing pEX-18Gm-KO-tsdA were isolated on 2216E agar plates supplemented with $10 \%$ sucrose and ampicillin. Putative mutants were checked by PCR with primers tsdAup_F/tsdA-down_R. The same methods were used to construct other mutant strains using the corresponding primers listed in Supplementary Table S2.

\section{Analytical techniques for the determination of different sulfur compounds}

For the measurement of thiosulfate, sulfate, ZVS and tetrathionate, wild type E. flavus $21-3$ and corresponding mutants were grown at $28^{\circ} \mathrm{C}$ in ASW 2216E supplemented with $40 \mathrm{mM}$ thiosulfate. Concentrations of thiosulfate and sulfate in the medium were measured by iodometric and barium sulfate turbidimetry respectively [51, 52]. Concentrations of tetrathionate were monitored by HPLC (ThermoFisher U3000, Scientific, USA) fitted with a syncronis C18 column $(250 \mathrm{~mm} \times 4.6 \mathrm{~mm}, 5 \mu \mathrm{m})$ (Thermo Scientific, USA). The column was eluted with $50 \mathrm{mM}$ $\mathrm{KH}_{2} \mathrm{PO}_{4}$ (pH adjusted to 2.68 with phosphoric acid) at a flow rate of $1.5 \mathrm{~mL} / \mathrm{min}$, and UV detection at $215 \mathrm{~nm}$ was used to identify product peaks. ZVS $\left(\mathrm{S}_{8}\right)$ was extracted from cultured medium using dichloromethane according to the method described in Houghton et al. [21]. Briefly, $1 \mathrm{~mL}$ sample was extracted three times using a total of $5 \mathrm{~mL}$ dichloromethane. The extracted dichloromethane was measured on a UV-Vis spectrometer (Infinite M1000 Pro; Tecan, Männedorf, Switzerland) at $270 \mathrm{~nm}$.

\section{Identification of tsdA, soxB, sdoA, and $s d o B$ homologs in bacterial genomes}

$T s d A$, sox $B, s d o A$, and $s d o B$ homologs were identified in bacterial genomes based on BLASTP searches against assembled genomes including archaea and bacteria at Integrated Microbial Genomes (IMG) [53]. Amino acid sequences of TsdA, SoxB, SdoA, and SdoB from E. flavus 21-3, TsdA from A. vinosum DSM 180 (ADC61061.1), and SoxB from Paracoccus denitrificans (CAA55824.2) were used as queries. All positive hits were manually checked for cooccurrence of the soxYZ genes. To find homolog genes of tsdA, soxB, sdoA and $s d o B$ in the genomes of other Erythrobacter (72 assembled genomes, download at May-2019) obtained from National Center for Biotechnology Information (NCBI), a detailed blast was run in Galaxy [54]. All hits used in further analysis had an identity of $40 \%$ or higher.

\section{Results}

\section{Screening, purification, and identification of deep- sea bacteria possessing potential thiosulfate oxidation capability}

During the course of screening of deep-sea bacteria possessing potential thiosulfate oxidation capability, strain 21-3 attracted our attention because it produced an obvious milky substance in the culture supplemented with $40 \mathrm{mM}$ thiosulfate after two days of incubation (Fig. 1a), which is a typical indicator of ZVS formation. The cells of strain 21-3 were subsequently purified three times using the dilution-toextinction technique at $28^{\circ} \mathrm{C}$. The $16 \mathrm{~S}$ rRNA gene sequence of strain 21-3 (accession no. MN744319) shared a high similarity of $99.93 \%$ with Erythrobacter flavus SW-46 ${ }^{\mathrm{T}}$. In addition, strain 21-3 also clustered with $E$. flavus SW-46 according to phylogenetic analysis (Supplementary Fig. S1). The ANI between strain 21-3 and other two strains E. flavus VG1 (accession no. ASM223761) and E. flavus KJ5 (accession no. ASM429625) was $97.56 \%$ and $97.40 \%$, respectively, which were higher than the accepted threshold (ANI value of 94\%) for same species [55] Thus, strain 21-3 was identified as a member of $E$. flavus and designated as $E$. flavus $21-3$ in this study.

\section{Identification and characterization of sulfur globules produced by $E$. flavus 21-3 combining with SEM, EDS, Raman spectrum, and TEM}

To gain insight into the milky white substance produced by E. flavus 21-3 when cultured with thiosulfate, the white substance was subjected to SEM and EDS analyses. SEM results showed that bacterial cells were embedded in globular crystals (Fig. 1b), which is similar to the reported extracellular sulfur globules produced by Hydrogenovibrio thermophiles, a chemolithomixotrophic bacterium that uses thiosulfate as an energy source [56]. These crystals were further identified as elemental sulfur by EDS (Fig. 1c). Raman spectrum of the cyclooctasulfur standard was characterized by two strong peaks at 154 and $220 \mathrm{~cm}^{-1}$ corresponding to the bending and stretching modes of the eightfold ring and a third peak at $473 \mathrm{~cm}^{-1}[4,10]$. These typical characteristics of $S_{8}$ were also found in the analysis of the white substance from E. flavus 21-3 (Fig. 1d).

To further characterize the ZVS intermediate formed in E. flavus 21-3, sulfur globules produced by the cells were purified and checked with TEM. TEM results showed that the separated sulfur globules (of size $400 \mathrm{~nm}$ ) were coated with carbon (Fig. 2a) as previously described [57]. TEMEDS results of the separated sulfur globules (Fig. 2b) were accordant with those of SEM-EDS (Fig. 1c), confirming that $E$. flavus $21-3$ is capable to convert thiosulfate to ZVS. 
Fig. 1 E. flavus 21-3 produces ZVS when cultured in medium supplemented with thiosulfate. E. flavus 21-3 cultured in diluted 2216E without (a) or with $40 \mathrm{mM}$ thiosulfate (b). b SEM observation of ZVS produced by E. flavus 21-3. c Energy dispersive spectrum analysis of the selected area in b. d Raman spectra of the ZVS produced by E. flavus $21-3$ and standard $\mathrm{S}_{8}$.
A

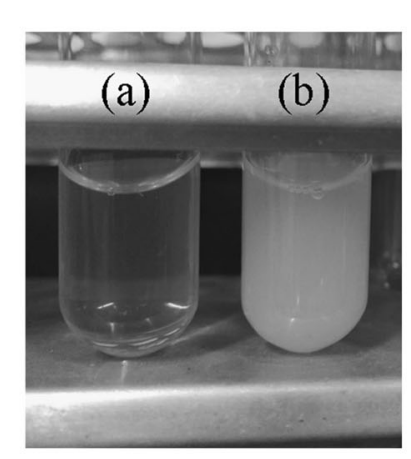

C

$\mathrm{D}$

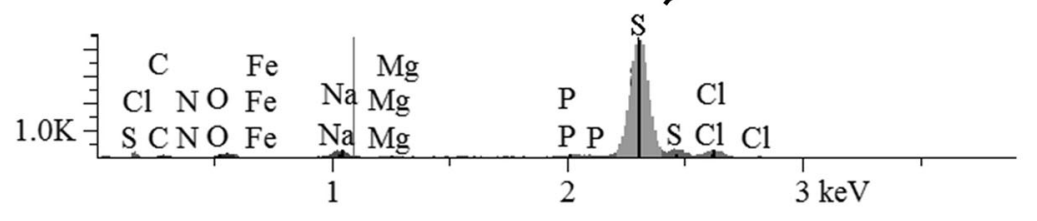

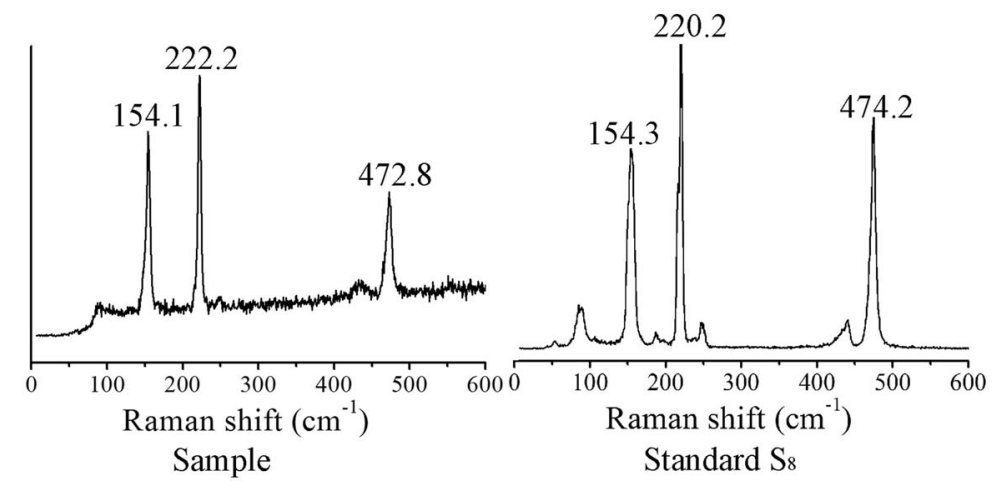

TEM was further conducted to observe the production of sulfur globules $\left(\mathrm{S}_{8}\right)$ throughout the growth period of $E$. flavus 21-3 that was cultured with $40 \mathrm{mM}$ thiosulfate. At the start of the early-exponential phase ( $12 \mathrm{~h}$ of incubation) many small solid globules were produced around the cells (Fig. 2c), while at the mid-exponential phase (cultured for $36 \mathrm{~h}$ ) only a few large, hollow globules were attached to the cells (Fig. 2d). These distinct morphological characteristics of the sulfur globules observed at different growth stages suggest that the sulfur globule may serve as an intermediate during the oxidation of thiosulfate, and indicated that $E$. flavus 21-3 might be a good candidate for the study of microbial thiosulfate oxidation.

\section{Genomic evidence of thiosulfate oxidation in E. flavus 21-3}

To obtain a genetic basis of the thiosulfate oxidation in $E$. flavus 21-3, the genome of E. flavus 21-3 was completely sequenced using PacBio RSII (Novogene Bioinformatics Technology Co. Ltd, Beijing, China), and the general genomic features are presented in Supplementary Table S3. The complete genome sequence and all genome information of E. flavus 21-3 have been deposited to GenBank (accession no. CP032228). When analyzing the E. flavus 21-3 genome sequence, we surprised to find only some genes encoding sulfotransferase and thioredoxin-disulfide reductase present, such as disulfide interchange, sulfite exporter, and proteins involved in the metabolism of assimilatory sulfate reduction (Supplementary Table S4). While most typical genes encoding proteins involved in thiosulfate oxidation (the Sox multienzyme complex, flavin cytochrome c-sulfide dehydrogenase, sulfide: quinone oxidoreductase, sulfite: acceptor oxidoreductase, and reverse-acting dissimilatory sulfite reductase) were absent. Given the fact that thiosulfate oxidation occurs in E. flavus 21-3, we speculated that a novel pathway may exist in E. flavus 21-3.

\section{Proteomic analyses of thiosulfate oxidation in E. flavus 21-3}

To better describe the mechanism of thiosulfate oxidation in E. flavus 21-3, a proteomic assessment of E. flavus 21-3 cultured with or without thiosulfate was performed. The results of this assay showed that 346 of 1068 and 508 of 948 proteins were significantly up-regulated when 
Fig. 2 Transmission electron microscopic observation of ZVS produced by $E$. flavus 21-3. a TEM image of purified ZVS produced by E. flavus 21-3. b Energy dispersive spectrum analysis of the separated ZVS shown in panel A. TEM images of $E$. flavus 21-3 cells mixed with ZVS when cultured for $12 \mathrm{~h}(\mathbf{c})$ or 36 $\mathrm{h}(\mathbf{d})$ in medium supplemented with $40 \mathrm{mM}$ thiosulfate.
A

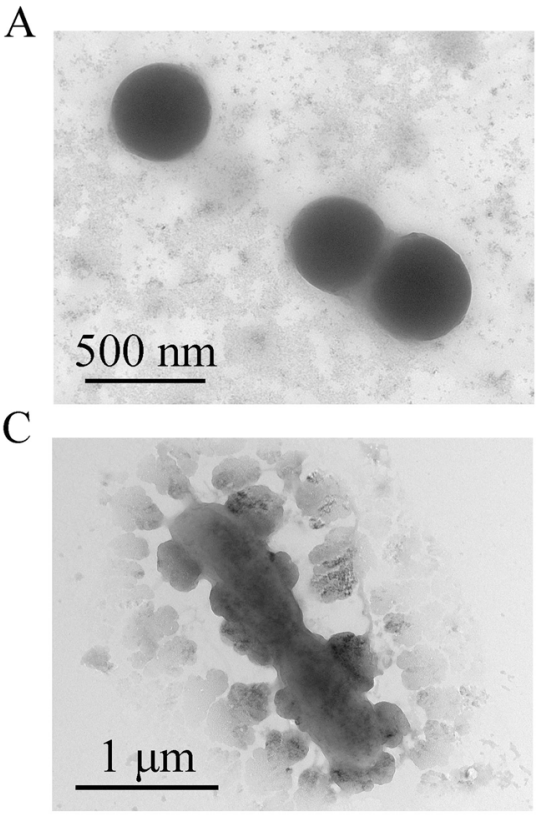

B

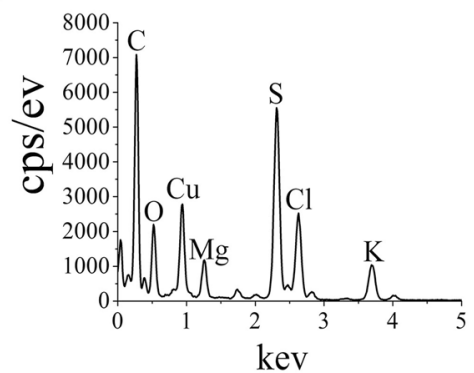

$\mathrm{D}$

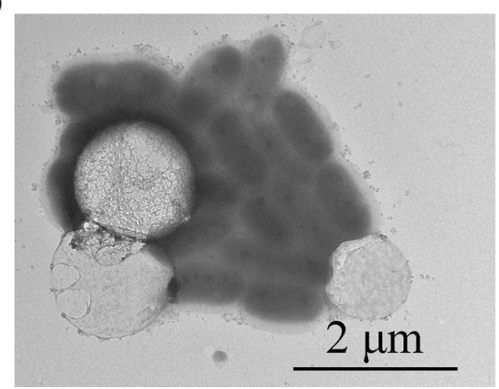

grown in culture containing thiosulfate at 18 and $36 \mathrm{~h}$, respectively $(P<0.05)$. After carefully analyzing this data, we found that the expression of a gene cluster including genes from D0Y83_01340 to D0Y83_01450 (locus tag) was upregulated invariably at both culture time points (Fig. 3a).

Within this gene cluster, the gene D0Y83_01395 encodes a protein homologous to the c-type cytochrome with $\mathrm{C} \times \times \mathrm{CH}$ motifs. Since SoxA and TsdA, the typical thiosulfate oxidation proteins, both have the $\mathrm{C} \times \times \mathrm{CH}$ motif (Supplementary Fig. S2), a phylogenetic analysis was carried out based on the alignment of typical SoxA and TsdA protein sequences. Protein encoded by the gene D0Y83_01395 clustered with TsdA (Supplementary Fig. S3a), which has been shown to play a key role in the formation of tetrathionate from thiosulfate $[58,59]$. Thus, the name $t s d A$ was designated to the gene D0Y83_01395, with the corresponding protein named TsdA. Given the importance of TsdA in the course of thiosulfate oxidation, we overexpressed and purified the TsdA of E. flavus 21-3 in E. coli. The apparent molecular mass of purified E. flavus 21-3 TsdA is $36 \mathrm{KD}$ (Supplementary Fig. S3b), larger than the homologous protein in A. vinosum (27 KD) [60]. The UV-Visible electronic absorption spectrum of the purified recombinant protein has an obvious absorption at $410 \mathrm{~nm}$ (Supplementary Fig. S3c), a typical indicator of the existence of cysteine-ligated heme in TsdA [58, 59], which confirms that the D0Y83_01395-encoded protein is a homolog of TsdA.

Within the upregulation gene cluster, proteins encoded by genes D0Y83_01365 and D0Y83_01435 were both annotated as "bifunctional metallophosphatase/5'-nucleotidases", and the protein encoded by gene D0Y83_01405 was annotated as " 5 '-nucleotidase $/ 3$ '-nucleotidase". Further BLASTP results showed that all three proteins possess a conserved domain named "thiosulfohydrolase SoxB", which is proposed to play a potential role in the cleavage of terminal sulfone groups [61]. The phylogenetic analysis (Supplementary Fig. S4a) and sequence alignment (Supplementary Fig. S4b) of D0Y83_01365, D0Y83_01405, and D0Y83_01435 encoding proteins with other published typical SoxBs further indicate that these three proteins might play SoxB-like function in E. flavus 21-3.

The protein encoded by gene DOY83_01345 is annotated as "MBL fold metallo-hydrolase" and possesses conserved polysulfide dioxygenase and rhodanase, which are proposed to involve in the oxidation of polysulfide and sulfur [62, 63]. In addition, gene D0Y83_08990 (beyond this cluster) encodes a protein that is highly similar to the protein encoded by gene D0Y83_01345 (Supplementary Fig. S5), also suspected to be involved in the oxidation of polysulfide and sulfur. The arrangement of the gene cluster encoding up-regulated proteins, together with gene D0Y83_08990 is shown in Fig. 3b.

\section{Genetic determination of key factors responsible for thiosulfate oxidation in E. flavus 21-3}

Next, we sought to thoroughly investigate the roles of the key genes identified in the proteomic analysis by creating gene knockouts in vivo. After much effort, a genetic operating system was successfully constructed for the first time in the genus Erythrobacter. Notably, deletion of ts $d A$ (D0Y83_01395) and D0Y83_01365 almost completely disrupted the ability of E. flavus 21-3 mutants to form sulfur 

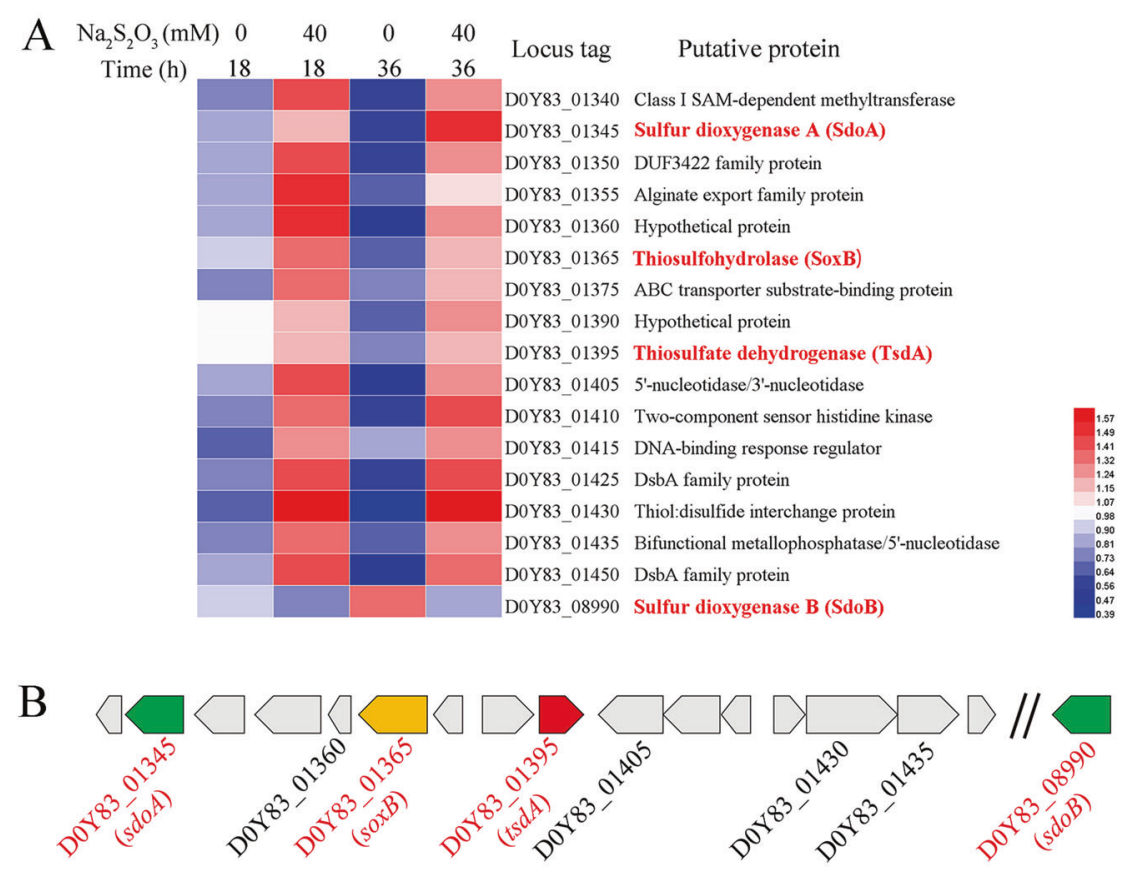

$\mathrm{C}$

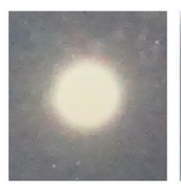

wild type

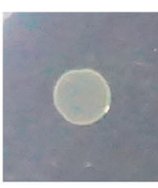

$\Delta t s d A$

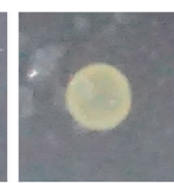

$\triangle \operatorname{sox} B$

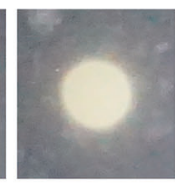

$\triangle s d o A$

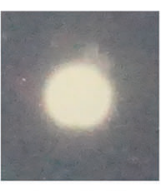

$\triangle s d o B$

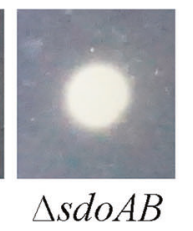

Fig. 3 Proteomic and genetic determination of key genes responsible for thiosulfate oxidation in $\boldsymbol{E}$. flavus 21-3. a Heatmap analyses of different expressed proteins in E. flavus 21-3 when cultured in medium supplemented with 0 or $40 \mathrm{mM}$ thiosulfate after $18 \mathrm{~h}$ and $36 \mathrm{~h}$, respectively. Expression of D0Y83_08990 (sdoB) is also shown for its high similarity with D0Y83_01345 (sdoA). b Arrangement of the corresponding gene cluster together with D0Y83_08990 (sdoB), possibly involved in thiosulfate oxidation as shown in a. c Genetic determination of genes involved in thiosulfate oxidation as shown in

globules when grown in the presence of thiosulfate (Fig. 3c), which demonstrates that these two genes play key roles in thiosulfate oxidation in E. flavus 21-3. Given the close phylogenetic relationship between D0Y83_01365 encoding protein and other SoxBs (Supplementary Fig. S4a), the gene D0Y83_01365 was designated as soxB with the corresponding protein name SoxB. Though D0Y83_01405 and D0Y83_01435 encoding proteins also possess the "thiosulfohydrolase SoxB" domain, deletion of D0Y83_01405 and D0Y83_01435 did not affect sulfur globule formation (Supplementary Fig. S6).

Deletion of D0Y83_01345 and D0Y83_08990 had no obvious influence on sulfur globule formation (Fig. 3c). However, compared with wild type, the ability of further ZVS oxidation was abolished in the mutant strain $\triangle D 0 Y 83 \_08990$, which suggests a potential function for D0Y83_08990 encoding protein in ZVS oxidation. Given a and $\mathbf{b}$. The capacity of E. flavus 21-3 wide type and corresponding mutants to produce extracellular sulfur globules was assessed using agar plates supplemented with $40 \mathrm{mM}$ thiosulfate. The formation of a white milky substance around the colonies indicates they are capable of thiosulfate oxidation, while the disappearance of the substance around the colonies indicates this capacity has been lost. The genes responsible for thiosulfate oxidation in E. flavus 21-3 (verified by gene disruption) are indicated in red in $\mathbf{a}$ and $\mathbf{b}$.

the high similarity of D0Y83_01345 and D0Y83_08990, we assigned SdoA (sulfur dioxygenase A) and SdoB (sulfur dioxygenase B) to D0Y83_01345 and D0Y83_08990 encoding proteins, respectively. Consistently, double mutant strain $\triangle s d o A B$ showed the same phenotype as that of the mutant strains $\triangle s d o A$ and $\triangle s d o B$ (Fig. 3c). The deletion of other genes, including D0Y83_01360 and D0Y83_01430, did not show any effect on thiosulfate oxidation (Supplementary Fig. S6), suggesting they might be not essential for thiosulfate metabolism in E. flavus 21-3.

\section{Thiosulfate oxidation in E. flavus 21-3 wild type and mutant strains}

To reveal the exact function of key genes ( $t s d A, \operatorname{sox} B, s d o A$, and $s d o B$ ) responsible for thiosulfate oxidation determined by proteomic and genetic methods, the stoichiometry of 

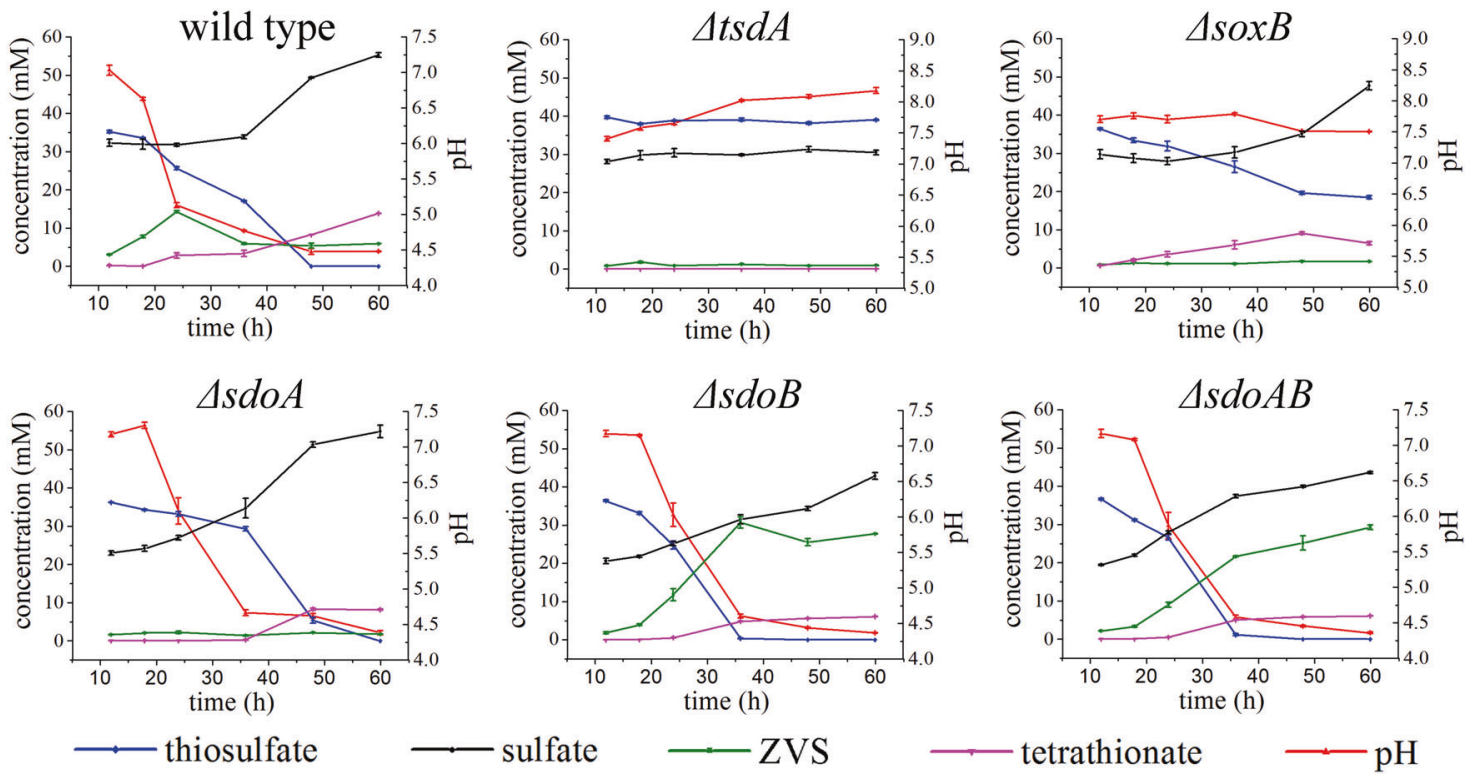

Fig. 4 Comparisons of thiosulfate oxidation, generation of sulfate, tetrathionate, and ZVS in E. flavus 21-3 wild type and corresponding mutants. The error bars indicate the standard deviation (S.D.) from two different biological replicates.

sulfur intermediates in the course of thiosulfate oxidation in E. flavus 21-3 wild type and mutants was determined. In wild type E. flavus 21-3, the concentration of thiosulfate decreased with the culture time, and reached zero after $48 \mathrm{~h}$ of incubation (Fig. 4). Meanwhile, the concentration of sulfate continued to increase throughout the culturing time $(\sim 60 \mathrm{~h})$, suggesting that thiosulfate was eventually converted to sulfate. The maximum accumulation of ZVS $\left(\mathrm{S}_{8}\right)$ in the medium appeared at $24 \mathrm{~h}$ and then dropped gradually to the detectable amount at the end of culturing time (Fig. 4), while the concentration of the other important intermediate tetrathionate increased slightly throughout the time course of the culture (Fig. 4). The existence of $S_{8}$ and tetrathionate in the medium implies that E. flavus 21-3 mediated incomplete oxidation of thiosulfate (Fig. 4). The $\mathrm{pH}$ of medium decreased across the culturing time, which strongly indicates the occurrence of sulfone oxidation in the course of thiosulfate oxidation in E. flavus 21-3 [61].

Interestingly, the concentration of thiosulfate was constant and tetrathionate was not detected in the $\Delta t s d A$ mutant culture (Fig. 4). Given that thiosulfate is generally converted to tetrathionate [12], and the fact that tetrathionate was detected in wild type E. flavus $21-3$ but not in the $\Delta t s d A$ mutant, it is reasonable to deduce that TsdA mediates the first step of thiosulfate oxidation in this bacterium. It therefore makes sense that neither ZVS nor extra sulfate was detected in the $\Delta t s d A$ mutant culture medium. In the mutant strain $\Delta \operatorname{sox} B$, the concentrations of thiosulfate and tetrathionate gradually decreased and increased respectively, while ZVS was not detected in the medium. Meanwhile, the sulfate concentration was lower in the mutant than that in the wild type, indicating the involvement of SoxB in liberating sulfone from tetrathionate $\left({ }^{-} \mathrm{O}_{3} \mathrm{~S}-\mathrm{S}-\mathrm{S}-\mathrm{SO}_{3}{ }^{-}\right)$during sulfate formation. Taken together, these results suggest that SoxB functions downstream of TsdA but upstream of the key step in ZVS formation.

Mutant strain $\triangle s d o A$ consumed $40 \mathrm{mM}$ thiosulfate after $60 \mathrm{~h}$ of incubation, without obvious accumulation of ZVS. This observation conflicts with the phenotype detected on agar plates (Fig. 3c). However, we also noticed that more ZVS accumulated in the $\Delta s d o B$ mutant than in the wild type, suggesting that SdoB might act as a key factor in ZVS metabolism. Quantitative real-time PCR analysis showed that expression of $s d o B$ was upregulated in the mutant $\triangle s d o A$ when the bacterium was cultured with $40 \mathrm{mM}$ thiosulfate (Supplementary Fig. S7), which explained the extremely low concentration of ZVS detected in $\Delta s d o A$. Consistently, the concentrations of thiosulfate, sulfate, tetrathionate, and ZVS in the double mutant strain $\triangle s d o A B$ showed similar patterns to those in $\triangle s d o B$, confirming the prominent function of $\mathrm{SdoB}$ in oxidation of ZVS in E. flavus 21-3.

Based on the combination of proteomic, genetic, and stoichiometric data on thiosulfate oxidation in E. flavus 21-3 we propose a novel thiosulfate oxidation pathway (Fig. 5). Briefly, thiosulfate oxidation in E. flavus 21-3 is initially mediated by TsdA, which converts thiosulfate to tetrathionate $[58,59]$. Tetrathionate is further hydrolyzed by SoxB to form sulfate and release $\mathrm{H}^{+}$, which decreases the environment $\mathrm{pH}$. The remaining sulfur atoms may attach to membrane-bound thiol groups or be added to other polysulfide species [10]. However, polysulfide (polythionate) is 


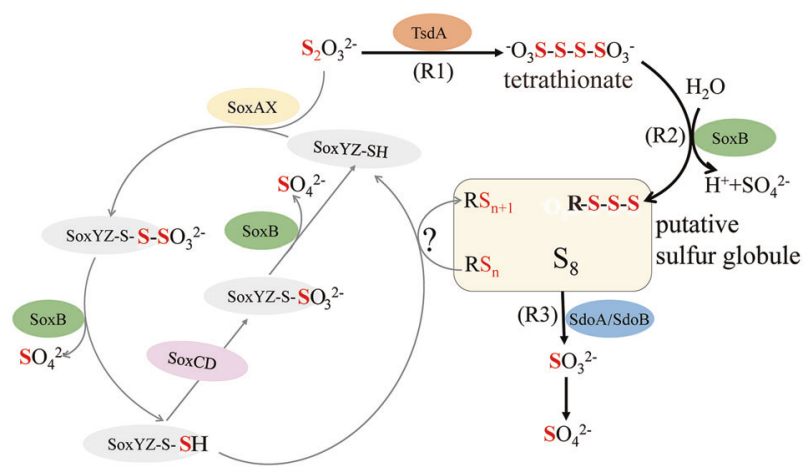

Fig. 5 The proposed novel thiosulfate oxidation pathway in $E$. flavus 21-3. Gray lines indicate the classical Sox pathway and black lines represent the novel pathway determined in E. flavus 21-3. The classical Sox pathway begins with the combination between thiosulfate and SoxYZ with the help of SoxAX, and results in a thiocysteine-Ssulfate residue ( $\mathrm{SoxYZ}-\mathrm{S}-\mathrm{SSO}_{3}{ }^{2-}$ ). Sulfate is liberated by hydrolysis (catalyzed by SoxB) to yield a polysulfide intermediate (SoxYZ-S-S ${ }^{-}$), which is subsequently oxidized by SoxCD to form a cysteine-S sulfate residue (SoxYZ-S-SO ${ }_{3}^{2-}$ ). Hydrolysis by SoxB releases sulfate and regenerates the SoxYZ complex (SoxYZ-SH). In the absence of SoxCD, sulfane splitting from the polysulfide intermediate (SoxYZ-S$\mathrm{S}^{-}$) in an obscure way results in polysulfide and free SoxYZ-SH. The novel pathway found in E. flavus 21-3 begins with the formation of tetrathionate from two molecular thiosulfate, catalyzed by TsdA (Reaction 1: R1). SoxB is responsible for liberating the sulfate from tetrathionate (instead of SoxYZ-S-S-SO ${ }_{3}$; Reaction 2: R2). The remaining sulfane is converted to polysulfide, and then relatively stable $\mathrm{S}_{8}$. The sulfur globule is finally oxidized by $\mathrm{SdoA} / \mathrm{SdoB}$, with sulfite as the intermediate product (Reaction 3: R3). Sulfite is nonenzymatically/enzymatically converted to sulfate. SoxAX sulfur oxidation c-type cytochrome, SoxB thiosulfohydrolase, SoxYZ thiosulfate oxidation carrier protein, SoxCD sulfur oxidation protein. TsdA thiosulfate dehydrogenase, $\mathrm{SdoA} / \mathrm{SdoB}$ sulfur dioxygenase $\mathrm{A} /$ sulfur dioxygenase $\mathrm{B}$.

unstable in acidic conditions and is therefore partly converted to stable cyclooctasulfur $S_{8}[8,64,65]$, forming the putative sulfur globules. In the presence of $\mathrm{SdoA} / \mathrm{SdoB}$, sulfur globules are further oxidized to sulfite and then nonenzymatically/enzymatically converted to sulfate.

\section{Wide distribution of the novel thiosulfate oxidation pathway determined in E. flavus 21-3}

To explore homologs of TsdA, SoxB, and SdoA/SdoB in other Erythrobacter species, we searched all assembled genomes of Erythrobacter in the NCBI database. Protein sequences PHR02631.1, HAG37069.1, and HAD16915.1 in the Erythrobacter genomes of NORP101, UBA9459, and UBA9044, respectively, showed 99.9\% identity with TsdA, and $\mathrm{C} \times \times \mathrm{CH}$ motifs were also identified in these sequences (Supplementary Fig. S8). Protein sequences HAG37075.1 and HAD16921.1 in the Erythrobacter genomes of UBA9459 and UBA9044 showed 97\% identity with SoxB (Supplementary Fig. S9). SdoA/SdoB homologs were found to exist in half of the assembled genomes of Erythrobacter, including in UBA9459 and UBA9044. A phylogenic tree was constructed using $\mathrm{SdoA} / \mathrm{SdoB}$ sequences from both Erythrobacter and Acidithiobacillus (the typical bacterium possessing ZVS oxidation) (Fig. 6). The results showed that SdoA and SdoB from Erythrobacter were clustered into a separate clade with those from Acidithiobacillus. Given the specific function of $\mathrm{SdoA} / \mathrm{SdoB}$ in ZVS oxidation, the resulting sequences clustered with $\mathrm{SdoA} / \mathrm{SdoB}$ were expected to have the same function. Overall, our analysis revealed that homologous sequences of TsdA, SoxB, and SdoA/SdoB were found in assembled Erythrobacter genomes UBA9459 and UBA9044, indicating that this novel thiosulfate oxidation pathway might exist in other Erythrobacter species.

Lastly, we checked the bacterial genomes available in IMG database to explore the existence of the novel thiosulfate oxidation pathway in other bacterial species. To ensure the accuracy of this analysis, stringent criteria were applied and only organisms containing both $t s d A$ and $s o x B$ homologous genes were considered. The search results showed that the set of genes were mainly identified in Alphaproteobacteria, Betaproteobacteria, Gammaproteobacteria, and Bacteroidetes (Supplementary Table S5). Moreover, the TsdA and SoxB homologs were also searched in the available metagenomes from IMG. The evalue was set as $1 \mathrm{e}^{-20}$ and the sequences with an identity more than $40 \%$ were selected. Totally, there were 18 (in total 103) metagenomes containing both TsdA and SoxB homologs (Supplementary Table S6). Notably, the identified bacteria containing both TsdA and SoxB homologs occur naturally in a variety of environments including land soil, acid mine drainage, sea water, and deep-sea sediment. To further clarify the functions of selected TsdA- and SoxB-like proteins, phylogenic trees were constructed using TsdA- and SoxB-like sequences obtained from the identified bacteria (Supplementary Table S5 and Fig. 7). The phylogenetic results showed that these TsdA- or SoxB-like proteins identified in different bacteria clustered with different typical TsdA or SoxB, suggesting that these bacteria might oxidize thiosulfate through the novel pathway. Given the key roles of TsdA and SoxB in this novel pathway and their broad distribution in bacteria, we propose that the novel thiosulfate oxidation pathway identified in E. flavus 21-3 exists in many other microorganisms.

\section{Discussion}

Sulfur is a key element whose transformation and status in the environment are critically dependent upon microbial activities. Individual microorganisms have evolved various enzyme systems to catalyze many conversions of sulfur 
Fig. 6 The consensus phylogenetic tree of SdoA and SdoB in E. flavus 21-3 with other related $\mathrm{SdoA} / \mathrm{SdoB}$ obtained from assembled genomes of Erythrobacter and Acidithiobacillus (accession numbers are indicated after each species name), constructed by the neighborjoining method. Sequences from Erythrobacter sp. UBA9044 and Erythrobacter sp. UBA9459 are underlined.

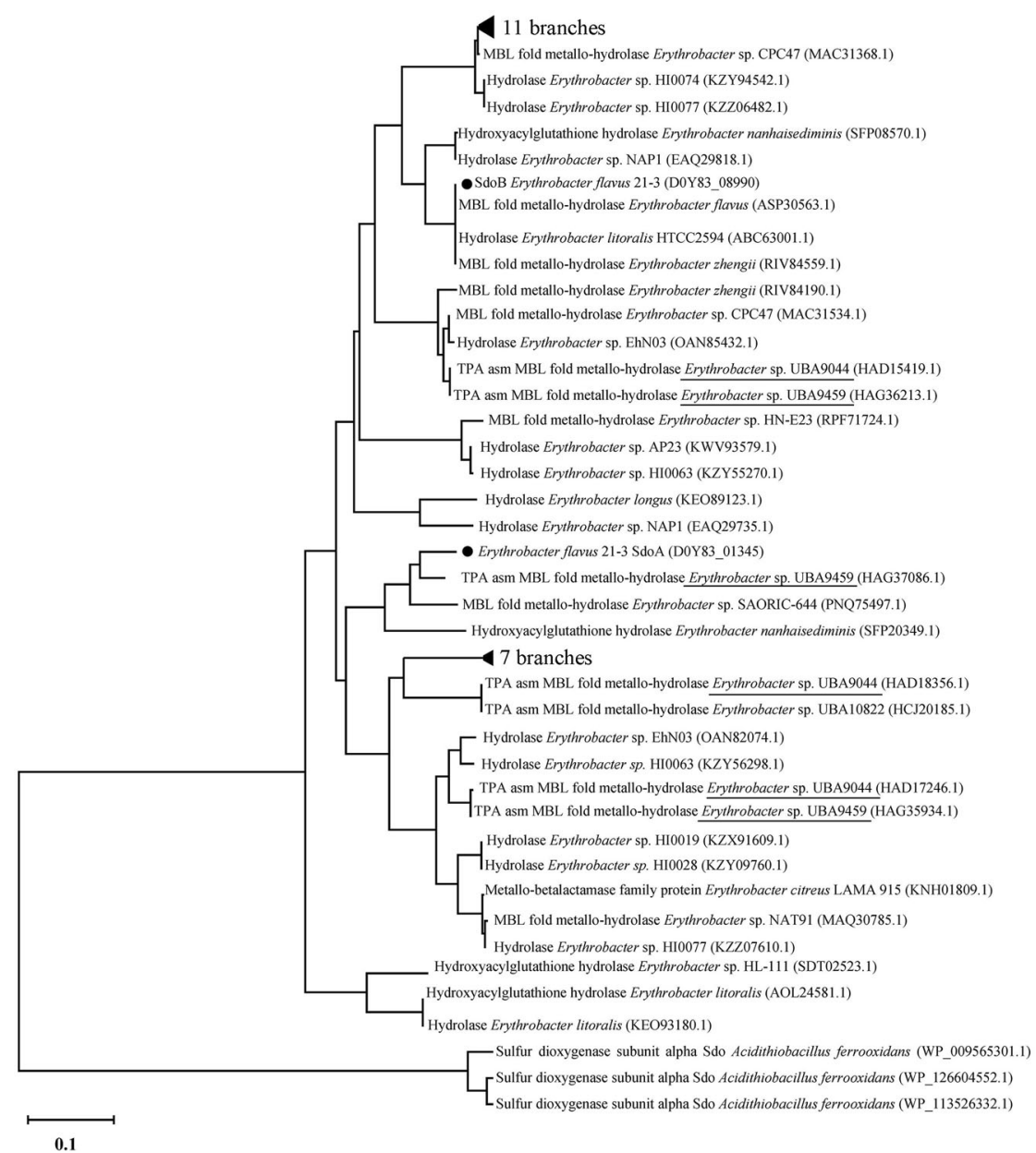

compounds between oxidation states [66]; some sulfur pathways and sulfur-converting enzymes are yet to be discovered and functionally characterized. Our discovery that TsdA and SoxB mediate the conversion of thiosulfate to ZVS in E. flavus 21-3 is totally unique compared with the three previously reported thiosulfate oxidation pathways [12], and key proteins associated with this novel pathway are widely distributed in many bacteria. Also, our findings add a new aspect to the current understanding of the source of ZVS in deep-sea cold seep.

Thiosulfate is known to play key roles in the sulfur cycle in marine sediments where it can be oxidized to sulfate by microorganisms in order to harness energy. TsdA and SoxB are two key proteins determined in the novel thiosulfate oxidation pathway we have described here. TsdA is a periplasmic enzyme belonging to the c-type cytochrome family present in a wide range of bacteria [67, 68]. The proposed function of TsdA is to oxidize thiosulfate to tetrathionate; in some case it acts as a bi-functional enzyme to reduce tetrathionate to thiosulfate [68]. In E. flavus 21-3, TsdA converts thiosulfate into tetrathionate (Fig. 4), which initiates the subsequent reaction in the novel thiosulfate oxidation pathway. In addition, the gene D0Y83_01390 located upstream of TsdA encoding gene (D0Y83_01395) was proposed to encode a cytochrome $c$ family protein TsdB, which might cooperate with TsdA to generate tetrathionate [69]. Tetrathionate is often used by bacteria as an electron acceptor and significantly stimulates the growth of many microbes [68]. Therefore, it is reasonable to propose that E. flavus 21-3 might benefit from the oxidation of thiosulfate. Moreover, TsdA is widely distributed among many bacteria (Supplementary Fig. S3), and we predict that this pathway is far more common than currently appreciated.

Tetrathionate is reported to be an intermediate in thiosulfate oxidation in purple sulfur bacteria, and further metabolism of tetrathionate is mediated by tetrathionate hydrolase which converts tetrathionate to thiosulfate, sulfate and sulfur products [25, 26, 70]. Based on the genetic and stoichiometric results from E. flavus 21-3 (Figs. 3, 4), we suggest that SoxB hydrolyzes tetrathionate to sulfate and ZVS. This is consistent with a previous study that proposed an essential role for SoxB in tetrathionate oxidation in $A$. kashmirensis [27]. It is worth noting that additional two 


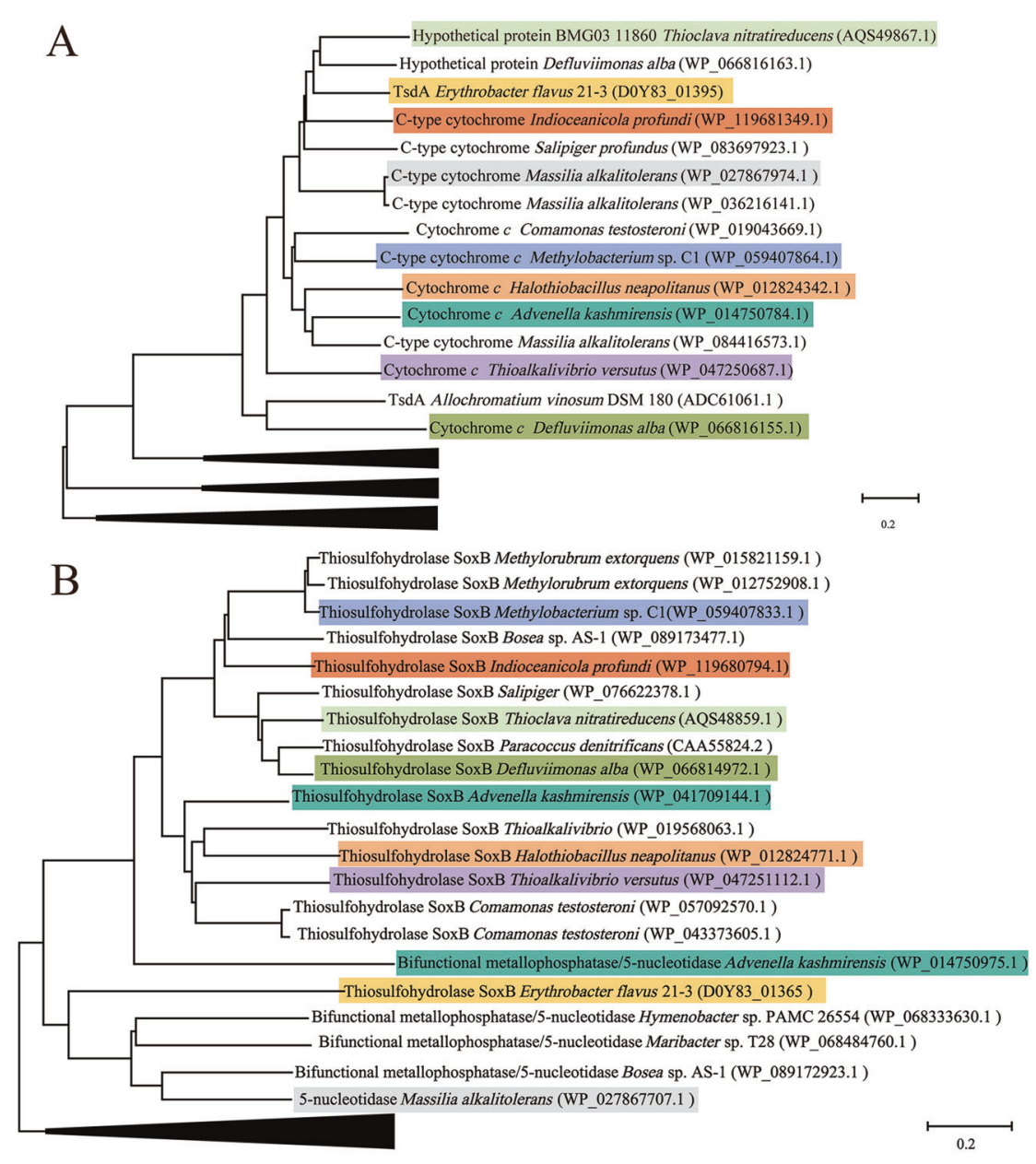

Fig. 7 Phylogenetic analysis of TsdA and SoxB homologs. The consensus phylogenetic tree of TsdA (a) and SoxB (b) in E. flavus 21-3 with other homologs obtained from public bacterial genomes (accession numbers are indicated after each species name) constructed by the neighbor-joining method. Branches shown in the tree represent sequences clustered with typical TsdA or SoxB, and each color indicates a specific species in a and b. Related species containing both TsdA and SoxB and their corresponding GenBank accession numbers are listed as

genes (D0Y83_01405 and D0Y83_01435) in E. flavus 21-3 also encode proteins belonging to the $5^{\prime}$-nucleotidase family that show similarity with SoxB (Supplementary Fig. S4a), and these two SoxB-like proteins also contain two kinds of conserved ligands of metal sites as that in typical SoxB (Supplementary Fig. S4B) [61]. We therefore speculate that D0Y83_01405 and D0Y83_01435 encoding proteins might hydrolyze tetrathionate and form ZVS and sulfate to some extent in the absent of SoxB. In fact, a small amount of ZVS was observed on agar plates supplemented with thiosulfate in the $\Delta \operatorname{sox} B$ mutant (Fig. 3c), and the concentration of sulfate increased during the $48-60 \mathrm{~h}$ along with the decrease of tetrathionate in $\triangle \operatorname{sox} B$ mutant (Fig. 4). However, the deletion of D0Y83_01405 and D0Y83_01435 did not influence the formation of ZVS, which confirms the follows: Advenella kashmirensis: GCA_000219915.3; Methylobacterium sp. C1: GCA_001854385.1; Indioceanicola profundi: GCA_003568845.1; Thioclava nitratireducens: GCA_000024765.1; Defluviimonas alba: GCA_000024765.1; Halothiobacillus neapolitanus: GCA_000024765.1; Thioalkalivibrio versutus: GCA_001020955.1; Massilia alkalitolerans: GCA_000427785.1, and E. flavus 21-3: GCA_008932225.1.

dominant tetrathionate oxidation function of SoxB in $E$. flavus 21-3.

In E. flavus 21-3, ZVS can be further oxidized to sulfite by $\mathrm{SdoA} / \mathrm{SdoB}$, in a process strictly limited by the concentration of oxygen [63]. This explains the discrepancy of ZVS formation between agar plates and aerobic liquid medium in E. flavus 21-3 wild type and $\Delta$ soxB and $\Delta s d o A$ mutant strains: the concentrations of ZVS decreased after a $24 \mathrm{~h}$ incubation of the liquid culture, but remained the same on agar plates throughout the culturing time (Figs. 3c, 4). Sulfite is easily oxidized to sulfate in the presence of oxygen, and this indeed happened in E. flavus 21-3 (Figs. 4, 5). There are in fact two steps that would produce sulfate in the course of thiosulfate oxidation in this novel pathway (Fig. 5), and sulfate is no doubt a very 
important sulfur compound that affects the abundance of sulfate-reducing microorganisms to a great extent [66]. Notably, on a global scale, recent estimates suggest that the remineralisation of up to $29 \%$ of the organic matter deposited to the seafloor is facilitated by sulfate-reducing microorganisms [66]. Given the isolation niches of $E$. flavus $21-3$ and wide distribution of TsdA/SoxB/SdoA/ $\mathrm{SdoB}$ in other bacteria, we propose that the contribution of microorganisms possessing this thiosulfate oxidation pathway to the sulfur cycle in the deep-sea cold seep can't be ignored. Future efforts are required to test the functional role of E. flavus 21-3 in thiosulfate oxidation in situ and to explore the existence of this novel pathway in other cold-seep bacterial isolates.

\section{Data deposit}

The genome data of E. flavus 21-3 have been deposited to the NCBI with the accession number of CP032228. The mass spectrometry proteomics data have been deposited to the Proteome Xchange Consortium via the PRIDE [71] partner repository with the dataset identifier PXD016502.

Acknowledgements We thank Dr Shawna Hiley (Life Science Editors, Edmonton, AB, Canada) for helpful comments on the manuscript. We thank Dr Ben C. Berks for kindly providing the plasmid pEC86. We thank Dr Lei Cao from the Institute of Oceanology for providing the chemical parameters of sampling site. This work was funded by the Strategic Priority Research Program of the Chinese Academy of Sciences (Grant no. XDA22050301), China Ocean Mineral Resources R\&D Association Grant (Grant no. DY135B2-14), National Key R and D Program of China (Grant no. 2018YFC0310800), the Taishan Young Scholar Program of Shandong Province (tsqn20161051), and Qingdao Innovation Leadership Program (Grant no. 18-1-2-7-zhc) for Chaomin Sun. This study is also funded by the CAS Interdisciplinary Innovation Team (Grant no. JCTD-2018-12) and Open Research Project of National Major Science \& Technology Infrastructure (RV KEXUE) (Grant no. NMSTIKEXUE2017K01).

Author contributions $\mathrm{JZ}$ and CS conceived and designed the study; JZ conducted most of the experiments; RL and XZ collected the samples from the deep-sea cold seep; SX helped to perform the Raman spectra analysis; RC helped to search protein homologs from public genomes and metagenomes; JZ and CS lead manuscript writing and all authors contributed to and reviewed the manuscript.

\section{Compliance with ethical standards}

Conflict of interest The authors declare that they have no conflict of interest.

Publisher's note Springer Nature remains neutral with regard to jurisdictional claims in published maps and institutional affiliations.

Open Access This article is licensed under a Creative Commons Attribution 4.0 International License, which permits use, sharing, adaptation, distribution and reproduction in any medium or format, as long as you give appropriate credit to the original author(s) and the source, provide a link to the Creative Commons license, and indicate if changes were made. The images or other third party material in this article are included in the article's Creative Commons license, unless indicated otherwise in a credit line to the material. If material is not included in the article's Creative Commons license and your intended use is not permitted by statutory regulation or exceeds the permitted use, you will need to obtain permission directly from the copyright holder. To view a copy of this license, visit http://creativecommons. org/licenses/by/4.0/.

\section{References}

1. Labrado AL, Brunner B, Bernasconi SM, Peckmann J. Formation of large native sulfur deposits does not require molecular oxygen. Front Microbiol. 2019;10:24.

2. White SN. Laser Raman spectroscopy as a technique for identification of seafloor hydrothermal and cold seep minerals. Chem Geol. 2009;259:240-52.

3. White SN, Dunk R, Peltzer ET, Freeman J, Brewer PG. In situ Raman analyses of deep-sea hydrothermal and cold seep systems (Gorda Ridge and Hydrate Ridge). Geochem Geophys Geosyst. 2006;7:1-12.

4. Zhang X, Du Z, Zheng R, Luan Z, Qi F, Cheng K, et al. Development of a new deep-sea hybrid Raman insertion probe and its application to the geochemistry of hydrothermal vent and cold seep fluids. Deep-Sea Res Part I-Oceanogr Res Pap. 2017;123:1-12.

5. Gleeson DF, Pappalardo R, Anderson M, Grasby S, Mielke R, Wright $\mathrm{K}$, et al. Biosignature detection at an Arctic analog to Europa. Astrobiology. 2012;12:135-50.

6. Hamilton TL, Jones DS, Schaperdoth I, Macalady JL. Metagenomic insights into $S(0)$ precipitation in a terrestrial subsurface lithoautotrophic ecosystem. Front Microbiol. 2015;5:756.

7. Taylor CD, Wirsen CO, Gaill F. Rapid microbial production of filamentous sulfur mats at hydrothermal vents. Appl Environ Microbiol. 1999;65:2253-5.

8. Kamyshny A Jr, Ferdelman TG. Dynamics of zero-valent sulfur species including polysulfides at seep sites on intertidal sand flats (Wadden Sea, North Sea). Mar Chem. 2010;121:17-26.

9. Fossing H. Distribution and fate of sulfur intermediates-sulfite, tetrathionate, thiosulfate, and elemental sulfur-in marine sediments. In: Amend JP, Edwards KJ, Lyons TW editors. Sulfur biogeochemistry: past and present. Colorado, USA: Geological Society of America; 2004. p. 97-116.

10. Berg JS, Schwedt A, Kreutzmann AC, Kuypers MM, Milucka J. Polysulfides as intermediates in the oxidation of sulfide to sulfate by Beggiatoa spp. Appl Environ Microbiol. 2014;80:629-36.

11. Jørgensen BB. A thiosulfate shunt in the sulfur cycle of marine sediments. Science. 1990;249:152-4.

12. Ghosh W, Dam B. Biochemistry and molecular biology of lithotrophic sulfur oxidation by taxonomically and ecologically diverse bacteria and archaea. FEMS Microbiol Rev. 2009;33:999-1043.

13. Meyer B, Imhoff JF, Kuever J. Molecular analysis of the distribution and phylogeny of the soxB gene among sulfur-oxidizing bacteria-evolution of the Sox sulfur oxidation enzyme system. Environ Microbiol. 2007;9:2957-77.

14. Friedrich CG, Rother D, Bardischewsky F, Quentmeier A, Fischer J. Oxidation of reduced inorganic sulfur compounds by bacteria: emergence of a common mechanism? Appl Environ Microbiol. 2001;67:2873-82.

15. Pronk J, Meulenberg R, Hazeu W, Bos P, Kuenen J. Oxidation of reduced inorganic sulphur compounds by Acidophilic thiobacilli. FEMS Microbiol Rev. 1990;75:293-306.

16. Grimm F, Franz B, Dahl C. Thiosulfate and sulfur oxidation in purple sulfur bacteria, In: Dahl C, Friedrich CG editors. 
Heidelberg, Germany: Microbial sulfur metabolism. Springer; 2008. p. 101-16.

17. Prange A, Chauvistré R, Modrow H, Hormes J, Trüper HG, Dahl C. Quantitative speciation of sulfur in bacterial sulfur globules: Xray absorption spectroscopy reveals at least three different species of sulfur. Microbiology. 2002;148:267-76.

18. Mußmann M, Hu FZ, Richter M, De Beer D, Preisler A, Jørgensen $\mathrm{BB}$, et al. Insights into the genome of large sulfur bacteria revealed by analysis of single filaments. PLOS Biol. 2007;5:e230.

19. Sakurai H, Ogawa $T$, Shiga $M$, Inoue K. Inorganic sulfur oxidizing system in green sulfur bacteria. Photosynth Res. 2010;104:163-76.

20. Gregersen LH, Bryant DA, Frigaard NU. Mechanisms and evolution of oxidative sulfur metabolism in green sulfur bacteria. Front Microbiol. 2011;2:116.

21. Houghton J, Foustoukos D, Flynn T, Vetriani C, Bradley AS, Fike D. Thiosulfate oxidation by Thiomicrospira thermophila: metabolic flexibility in response to ambient geochemistry. Environ Microbiol. 2016;18:3057-72.

22. Kelly DP, Shergill JK, Lu WP, Wood AP. Oxidative metabolism of inorganic sulfur compounds by bacteria. Antonie van Leeuwenhoek. 1997;71:95-107.

23. Lu WP, Kelly DP. Cellular location and partial purification of the 'thiosulphate-oxidizing enzyme' and 'trithionate hydrolyase' from Thiobacillus tepidarius. Microbiology. 1988;134:877-85.

24. Dam B, Mandal S, Ghosh W, Gupta SKD, Roy P. The $S_{4}$-intermediate pathway for the oxidation of thiosulfate by the chemolithoautotroph Tetrathiobacter kashmirensis and inhibition of tetrathionate oxidation by sulfite. Res Microbiol. 2007; 158:330-8.

25. De Jong GA, Hazeu W, Bos P, Kuenen JG. Isolation of the tetrathionate hydrolase from Thiobacillus acidophilus. Eur J Biochem. 1997;243:678-83.

26. Meulenberg R, Pronk JT, Hazeu W, Bos P, Kuenen JG. Oxidation of reduced sulphur compounds by intact cells of Thiobacillus acidophilus. Arch Microbiol. 1992;157:161-8.

27. Pyne P, Alam M, Rameez MJ, Mandal S, Sar A, Mondal N, et al. Homologs from sulfur oxidation (Sox) and methanol dehydrogenation (Xox) enzyme systems collaborate to give rise to a novel pathway of chemolithotrophic tetrathionate oxidation. Mol Microbiol. 2018;109:169-91.

28. Hensen D, Sperling D, Trüper HG, Brune DC, Dahl C. Thiosulphate oxidation in the phototrophic sulphur bacterium Allochromatium vinosum. Mol Microbiol. 2006;62:794-810.

29. Frigaard N-U, Dahl C. Sulfur metabolism in phototrophic sulfur bacteria. Adv Micro Physiol. 2008;54:103-200.

30. Imhoff JF. The phototrophic alpha-proteobacteria. Prokaryotes. 2006;5:41-64.

31. Robertson LA, Kuenen JG. The colorless sulfur bacteria. Prokaryotes. 2006;2:985-1011.

32. Kelly DP, Wood AP. Reclassification of some species of Thiobacillus to the newly designated genera Acidithiobacillus gen. nov., Halothiobacillus gen. nov. and Thermithiobacillus gen. nov. Int J Syst Evol Microbiol. 2000;50:511-6.

33. Tonon LAC, Moreira APB, Thompson F. The family Erythrobacteraceae. In: Rosenberg E, DeLong EF, Lory S, Stackebrandt E, Thompson F, editors. The Prokaryotes: alphaproteobacteria and betaproteobacteria, https://doi.org/10. 1007/978-3-642-30197-1_376. Berlin, Heidelberg: Springer Berlin Heidelberg; 2014. p 213-35.

34. Zheng Q, Lin W, Liu Y, Chen C, Jiao N. A comparison of 14 Erythrobacter genomes provides insights into the genomic divergence and scattered distribution of phototrophs. Front Microbiol. 2016;7:984.
35. Nakazawa M, Nishida H. Effects of light and oxygen on the enlargement of Erythrobacter litoralis spheroplasts. J Gen Appl Microbiol. 2017;63:58-61.

36. Kolber ZS, Gerald F, Lang AS, Beatty JT, Blankenship RE, VanDover CL, et al. Contribution of aerobic photoheterotrophic bacteria to the carbon cycle in the ocean. Science. 2001;292:2492-5.

37. Hwang YO, Kang SG, Woo JH, Kwon KK, Sato T, Lee EY, et al. Screening enantioselective epoxide hydrolase activities from marine microorganisms: detection of activities in Erythrobacter spp. Mar Biotechnol. 2008;10:366-73.

38. Woo JH, Hwang YO, Kang SG, Lee HS, Cho JC, Kim SJ. Cloning and characterization of three epoxide hydrolases from a marine bacterium, Erythrobacter litoralis HTCC2594. Appl Microbiol Biot. 2007;76:365-75.

39. Nakama K, Medina M, Lien A, Ruggieri J, Collins K, Johnson HA. Heterologous expression and characterization of the manganese-oxidizing protein from Erythrobacter sp. strain SD21. Appl Environ Microbiol. 2014;80:6837-42.

40. Fang $\mathrm{C}$, Wu YH, Sun C, Wang H, Cheng H, Meng FX, et al. Erythrobacter zhengii sp. nov., a bacterium isolated from deep-sea sediment. Int J Syst Evol Microbiol. 2018;69:241-8.

41. Chen X, Liu J, Xu Y, Wang Y, Yan X. Erythrobacter nanhaiensis sp. nov., a novel member of the genus Erythrobacter isolated from the South China Sea. Curr Microbiol. 2019;76:57-62.

42. Xu M, Xin Y, Yu Y, Zhang J, Zhou Y, Liu H, et al. Erythrobacter nanhaisediminis sp. nov., isolated from marine sediment of the South China Sea. Int J Syst Evol Microbiol. 2010;60: 2215-20.

43. Li J, Li L, Bai S, Ta K, Xu H, Chen S, et al. New insight into the biogeochemical cycling of methane, $\mathrm{S}$ and $\mathrm{Fe}$ above the sulfatemethane transition zone in methane hydrate-bearing sediments: a case study in the Dongsha area, South China Sea. Deep-Sea Res Part I-Oceanogr Res Pap. 2019;145:97-108.

44. Wu S, Liu G, Jin W, Xiu P, Sun C. Antibiofilm and anti-infection of a marine bacterial exopolysaccharide against Pseudomonas aeruginosa. Front Microbiol. 2016;7:102.

45. Kumar S, Stecher G, Li M, Knyaz C, Tamura K. MEGA X: molecular evolutionary genetics analysis across computing platforms. Mol Biol Evol. 2018;35:1547-9.

46. Pritchard L, Glover RH, Humphris S, Elphinstone JG, Toth IK. Genomics and taxonomy in diagnostics for food security: softrotting enterobacterial plant pathogens. Anal Methods. 2016;8:12-24.

47. Müller FH, Bandeiras TM, Urich T, Teixeira M, Gomes CM, Kletzin A. Coupling of the pathway of sulphur oxidation to dioxygen reduction: characterization of a novel membrane-bound thiosulphate: quinone oxidoreductase. Mol Microbiol. 2004;53:1147-60.

48. Deng W, Wang Y, Liu Z, Cheng H, Xue Y. HEMI: a toolkit for Illustrating heatmaps. PLOS ONE. 2014;9:e111988.

49. White BA. PCR cloning protocols: from molecular cloning to genetic engineering. Vol 67. Springer, Totowa: Humana Press; 1997.

50. Wu S, Zheng R, Sha Z, Sun C. Genome sequence of Pseudomonas stutzeri 273 and identification of the exopolysaccharide EPS273 biosynthesis locus. Mar Drugs. 2017;15:218.

51. Trüper H, Schlegel H. Sulphur metabolism in Thiorhodaceae I. Quantitative measurements on growing cells of Chromatium okenii. Antonie van Leeuwenhoek. 1964;30:225-38.

52. Kelly DP, Wood AP. Synthesis and determination of thiosulfate and polythionates. In: Colowick SP, Joshi MD, Jagannathan, Kaplan NO editors. Methods in enzymology. Amsterdam, North Holland: Elsevier;. 1994. p. 475-501.

53. Markowitz VM, Mavromatis K, Ivanova NN, Chen I-MA, Chu K, Kyrpides NC. IMG ER: a system for microbial genome 
annotation expert review and curation. Bioinformatics. 2009; 25:2271-8.

54. Cock PJA, Chilton JM, Grüning B, Johnson JE, Soranzo N. NCBI BLAST + integrated into Galaxy. GigaScience. 2015;4:39.

55. Richter M, Rosselló-Móra R. Shifting the genomic gold standard for the prokaryotic species definition. Proc Natl Acad Sci USA. 2009;106:19126-31.

56. Jiang L, Lyu J, Shao Z. Sulfur metabolism of Hydrogenovibrio thermophilus strain S5 and its adaptations to deep-sea hydrothermal vent environment. Front Microbiol. 2017;8:2513.

57. Cosmidis J, Templeton AS. Self-assembly of biomorphic carbon/ sulfur microstructures in sulfidic environments. Nat Commun. 2016;7:12812.

58. Grabarczyk DB, Chappell PE, Eisel B, Johnson S, Lea SM, Berks BC. Mechanism of thiosulfate oxidation in the SoxA family of cysteine-ligated cytochromes. J Biol Chem. 2015;290:9209-21.

59. Brito JA, Denkmann K, Pereira IA, Archer M, Dahl C. Thiosulfate dehydrogenase (TsdA) from Allochromatium vinosum structural and functional insights into thiosulfate oxidation. J Biol Chem. 2015;290:9222-38.

60. Brito JA, Gutierres A, Denkmann K, Dahl C, Archer M. Production, crystallization and preliminary crystallographic analysis of Allochromatium vinosum thiosulfate dehydrogenase TsdA, an unusual acidophilic c-type cytochrome. Acta Crystallogr F-Struct Biol Commun. 2014;70:1424-7.

61. Sauvé V, Roversi P, Leath KJ, Garman EF, Antrobus R, Lea SM, et al. Mechanism for the hydrolysis of a sulfur-sulfur bond based on the crystal structure of the thiosulfohydrolase SoxB. J Biol Chem. 2009;284:21707-18.

62. Xia Y, Lü C, Hou N, Xin Y, Liu J, Liu H, et al. Sulfide production and oxidation by heterotrophic bacteria under aerobic conditions. ISME J. 2017;11:2754.
63. Xin Y, Liu H, Cui F, Liu H, Xun L. Recombinant Escherichia coli with sulfide: quinone oxidoreductase and persulfide dioxygenase rapidly oxidises sulfide to sulfite and thiosulfate via a new pathway. Environ Microbiol. 2016;18:5123-36.

64. Florentino AP, Weijma J, Stams AJ, Sánchez Andrea I. Ecophysiology and application of acidophilic sulfur-reducing microorganisms. In: Rampelotto $\mathrm{P}$ editor. Biotechnology of extremophiles. Hamburg, Germany: Springer; 2016; p. 141-75.

65. Findlay AJ. Microbial impact on polysulfide dynamics in the environment. FEMS Microbiol Lett. 2016;363:fnw103.

66. Wasmund K, Mußmann M, Loy A. The life sulfuric: microbial ecology of sulfur cycling in marine sediments. Environ Microbiol Rep. 2017;9:323-44.

67. Denkmann K, Grein F, Zigann R, Siemen A, Bergmann J, van Helmont $\mathrm{S}$, et al. Thiosulfate dehydrogenase: a widespread unusual acidophilic c-type cytochrome. Environ Microbiol. 2012;14:2673-88.

68. Liu YW, Denkmann K, Kosciow K, Dahl C, Kelly DJ. Tetrathionate stimulated growth of $C$ ampylobacter jejuni identifies a new type of bi-functional tetrathionate reductase (TsdA) that is widely distributed in bacteria. Mol Microbiol. 2013;88:173-88.

69. Kurth JM, Brito JA, Reuter J, Flegler A, Koch T, Franke T, et al. Electron accepting units of the diheme cytochrome $c$ TsdA, a bifunctional thiosulfate dehydrogenase/tetrathionate reductase. J Biol Chem. 2016;291:24804-18.

70. Kanao T, Kamimura K, Sugio T. Identification of a gene encoding a tetrathionate hydrolase in Acidithiobacillus ferrooxidans. J Biotechnol. 2007;132:16-22.

71. Perez Riverol Y, Csordas A, Bai J, Bernal Llinares M, Hewapathirana S, Kundu DJ, et al. The PRIDE database and related tools and resources in 2019: improving support for quantification data. Nucleic Acids Res. 2018;47:D442-D450. 